\section{Helena Antipoff e a Sociedade Pestalozzi de Minas Gerais: filantropia e ciência em prol dos anormais}

\section{Helena Antipoff and Sociedade Pestalozzi of Minas Gerais: philanthropy and science for the abnormal}

\author{
Adriana Araújo Pereira Borges ${ }^{i}$ \\ i Professora, Faculdade de Educação/ \\ Universidade Federal de Minas Gerais. \\ Belo Horizonte - MG - Brasil \\ orcid.org/0000-0003-0493-0099 \\ adriana.borges@terra.com.br
}

\section{Esther Augusta Nunes Barbosa ${ }^{i i}$ \\ "Coordenadora de Educação Especial Inclusiva, Secretaria de Estado de Educação de Minas Gerais. Belo Horizonte - MG - Brasil \\ orcid.org/0000-0002-9037-7535 \\ augustaesther@gmail.com}

Recebido em 31 jul. 2018.

Aprovado em 28 ago. 2019.
BORGES, Adriana Araújo Pereira; BARBOSA, Esther Augusta Nunes. Helena Antipoff e a Sociedade Pestalozzi de Minas Gerais: filantropia e ciência em prol dos anormais. História, Ciências, Saúde - Manguinhos, Rio de Janeiro, v.26, supl., dez. 2019, p.163-177.

Resumo

A relação entre filantropia, poder público e conhecimento científico é analisada a partir da experiência de Helena Antipoff na Sociedade Pestalozzi de Minas Gerais. Essa instituição promoveu, na primeira metade do século $\mathrm{XX}$, iniciativas de auxílio às crianças "anormais". $\mathrm{O}$ apoio às classes especiais, o trabalho do Consultório Médico Pedagógico, a criação da Associação de Assistência ao Pequeno Jornaleiro, as atividades do Instituto Pestalozzi e a Fazenda do Rosário são exemplos de parcerias entre poder público e filantropia. A centralidade do nome de Helena Antipoff na Sociedade Pestalozzi imprimiu na instituição a marca de sua idealizadora. Formada na Europa, mais especificamente no Instituto JeanJacques Rousseau, Helena Antipoff conciliou a filantropia e a ciência em prol dos "anormais".

Palavras-chave: Sociedade Pestalozzi de Minas Gerais; Helena Antipoff (18921974); infância anormal; filantropia.

\section{Abstract}

The relationships between philanthropy, government, and scientific knowledge are analyzed through the experience of Helena Antipoff at the Sociedade Pestalozzi of Minas Gerais. In the first half of the twentieth century, this institution spearheaded welfare initiatives for "abnormal" children. Support for disabled people, the work of the Medical Education Office, the creation of an association for the care of newsboys, and the activities of the Pestalozzi Institute and Fazenda do Rosário farm are examples of partnerships between the authorities and philanthropic organizations. Today, Sociedade Pestalozzi is strongly associated with the identity of its founder. Educated in Europe, at Institut Jean-Jacques Rousseau, Helena Antipoff conciliated philanthropy and science for the good of the "abnormal."

Keywords: Sociedade Pestalozzi de Minas Gerais; Helena Antipoff (1892-1974); abnormal childhood; philanthropy. 
A Sociedade Pestalozzi de Minas Gerais (SPMG) foi criada em Belo Horizonte em 1932. Idealizada por Helena Antipoff, psicóloga russa que teve sua formação na Europa, principalmente no Instituto Jean-Jacques Rousseau (IJJR), localizado em Genebra, na Suíça, a SPMG organizou-se em um modelo híbrido, em que filantropia e poder público se entrelaçaram.

Dentre as suas iniciativas, destacam-se o apoio às classes especiais mineiras, o Consultório Médico Pedagógico, a Associação de Assistência ao Pequeno Jornaleiro e o Instituto Pestalozzi. A experiência da Sociedade Pestalozzi foi fundamental para o estabelecimento do Complexo Educacional do Rosário na década de 1940, na área rural da cidade de Ibirité, em Minas Gerais. Todas as entidades tinham como público-alvo crianças consideradas fora do padrão de normalidade pretendido na época. Eram consideradas crianças "anormais" aquelas com deficiência sensorial, física ou intelectual; as que apresentavam problemas comportamentais; crianças moradoras das ruas; e até mesmo as órfãs, "anormais" por viverem em abrigos. Como o termo "anormal" abarcava diversas condições, tanto médicas quanto sociais, a SPMG acabou promovendo a criação de entidades diversas, que ofertaram tanto a assistência médica e psicológica como a social e educacional.

As classes especiais foram abertas no sistema público de educação do estado de Minas Gerais em 1933. Crianças com deficiência, que não tinham acesso a escola, passaram a frequentar o sistema de ensino. No mesmo ano, foi criado o Consultório Médico Pedagógico, modelo inspirado no consultório do IJJR, onde médicos atendiam de forma voluntária, ao lado da psicóloga Helena Antipoff e de alunas da Escola de Aperfeiçoamento. As crianças atendidas pelo serviço eram encaminhadas por hospitais psiquiátricos ou por escolas, além da demanda voluntária da população, e não era cobrada a consulta dos que não podiam pagar.

Já a Associação de Assistência ao Pequeno Jornaleiro, de 1934, acolheu meninos que viviam nas ruas da capital mineira, muitos deles pequenos trabalhadores, principalmente vendedores de jornais.

Em 1935, foi criado o Instituto Pestalozzi, uma escola especial que funcionou como internato e constitui um importante exemplo da relação entre poder público e iniciativa privada, representada aqui pela SPMG.

Por fim, a obra maior, o complexo educacional da Fazenda do Rosário. A instituição funcionou como internato e externato, atendendo crianças com as mais diversas patologias, além de crianças sem deficiência. O local foi planejado para acolher as diferenças em um espectro muito mais amplo do que o da "excepcionalidade".

A criação da Sociedade Pestalozzi está inserida em um contexto específico, em que a filantropia se firmava como importante ferramenta para a promoção da proteção à infância. $\mathrm{O}$ lugar ocupado pela criança desde o início do século XX fez com que ela se constituísse como sujeito privilegiado de atenções e cuidados. Rizzini e Pilotti (2009) diferenciam caridade de filantropia. A filantropia esperava resultados concretos e imediatos, associando-se aos métodos científicos. Como caridade e filantropia tinham objetivos comuns, tornaram-se sinônimos com o tempo, ambas visando à preservação da ordem social.

No caso da Sociedade Pestalozzi de Minas Gerais, a proteção à infância possuía claramente compromisso científico, representado por sua idealizadora e primeira presidente. ${ }^{1}$ 
Russa de nascimento, Helena Antipoff estudou em Paris antes de ir para Genebra, onde fez parte da primeira turma de ciências da educação do Instituto Jean-Jacques Rousseau. Sua formação no instituto influenciou as ações da sociedade, que se firmaram, prioritariamente, em torno da questão dos "anormais".

Veremos que:

A análise do processo vivido por Antipoff ajuda a compreender a maneira como a atividade científica tornou-se o passaporte para muitos indivíduos que passaram por experiências de mudança cultural, durante o século XX, especialmente os cientistas que, buscando distanciar-se das intensas crises sociais europeias da primeira metade do século, vieram a construir a ciência no Novo Mundo (Campos, Lourenço, Antonini, 2002, p.30).

Ainda de acordo com Campos, Lourenço e Antonini (2002), podemos afirmar que histórias como a de Helena Antipoff ajudam a compreender a história da ciência e da educação nas Américas.

A formação na Suíça, país conhecido pelo protagonismo internacional no que diz respeito aos direitos humanos, ${ }^{2}$ contribuiu para que Antipoff assumisse um papel de liderança, tanto em Minas Gerais quanto no Brasil, em relação à infância "anormal".

A análise do protagonismo de Antipoff frente à Sociedade Pestalozzi foi realizada a partir do conceito de histórias cruzadas de Werner e Zimmermann (2004). Nessa perspectiva, este é um estudo de caso em que conceitos, instrumentos analíticos e práticas de trabalho com a criança considerada anormal são avaliados como resultado de processos complexos de cruzamento, nos quais as diferentes tradições nacionais e disciplinares assumem várias configurações. Em vez de analisar a difusão de ideias e práticas de entidades individuais, consideradas em si mesmas sem relação com o contexto, a perspectiva da história cruzada requer uma abordagem multidimensional. No caso da história da educação, mais especificamente da história da educação especial, sobretudo no contexto da expansão da escola moderna, com seu arsenal científico de medidas e procedimentos padronizados, o modelo de interpretação aqui utilizado é o de uma abordagem focada na produção de diferenças nos processos de recepção e reinterpretação.

Nesse sentido, é importante afirmar a centralidade do nome de Antipoff como personagem fundamental na história da educação especial no Brasil. Ratcliff (2018) argumenta que a atual historiografia da ciência tem questionado os chamados mitos de origem, que apontam a filiação de determinado pensamento ou prática. Apesar de o autor sugerir a necessidade de questionar a centralidade de certos personagens, ele indaga se essa seria uma "razão para rejeitar qualquer filiação na constituição das ciências" (p.246). Ainda segundo Ratcliff, alguns historiadores culturalistas ou influenciados pelo socioconstrutivismo passaram a negar a possibilidade de filiação de ideias ou práticas. No caso aqui apresentado, o nome de Antipoff é central, embora todo o seu trabalho tenha se desenvolvido a partir do estabelecimento de uma rede de colaboradores em diversas partes do país. O objetivo deste artigo é discutir a relação entre filantropia e poder público, tomando como referência a Sociedade Pestalozzi de Minas Gerais. Foram consultadas fontes primárias como boletins, revistas, cartas e documentos que fazem parte do acervo do Memorial Helena Antipoff, 
em Ibirité, Minas Gerais, e da Sala Helena Antipoff, localizada na Universidade Federal de Minas Gerais (UFMG).

As informações aqui apresentadas pertencem a um banco de dados que pretende reunir fontes primárias diversas que contribuam para a realização de pesquisas inéditas sobre a história da educação especial em sua intersecção com a história da psicologia e a história das ciências.

A análise dos dados se deu a partir da eleição das categorias centrais para este estudo: a constituição da SPMG, o assistencialismo praticado pela instituição na perspectiva da filantropia e a relação com o poder público.

Os documentos consultados dizem respeito principalmente aos registros de criação das instituições aqui descritas. Já a característica assistencialista da instituição pode ser percebida em diversas passagens nos números da revista Infância Excepcional: Estudo, Educação e Assistência ao Excepcional, publicada de forma irregular entre 1933 e 1979. Considerada primeiro boletim, depois nomeada revista, a publicação era voltada para profissionais das áreas de educação, saúde, psicologia e assistência social. Familiares de pessoas com deficiência e a sociedade de forma geral também eram seus leitores. A revista tratava de diversos assuntos ligados à "infância excepcional", como o próprio título revela. Sua publicação foi encerrada em 1979 por falta de verba.

Para discutir a estreita relação com o poder público, foi consultada a correspondência de Helena Antipoff com Helena Dias Carneiro, uma de suas colaboradoras. Vivendo no Rio de Janeiro, Helena Carneiro fazia a ponte entre Antipoff e políticos importantes, como Anísio Teixeira.

A centralidade da criança, a preocupação com sua escolarização e com as questões relacionadas ao trabalho infantil passaram a ser foco de diversas iniciativas estatais e não estatais a partir do início do século XX no Brasil. A criança "anormal" passa a ser objeto de atenção, e instituições públicas e privadas são criadas para acolher essa população. Em Minas Gerais, a atuação de Helena Antipoff à frente da SPMG imprimiu na instituição características singulares, que serão discutidas adiante.

\section{Helena Antipoff e a proteção à infância: a influência do Instituto Jean-Jacques Rousseau e do período na Rússia}

As atividades do IJJR começaram em 1912. À sua frente, Pierre Bovet e Édouard Claparède. Bovet, filósofo de formação e pesquisador experimental, tinha como interesse central compreender o lugar da educação na criação de uma sociedade solidária e pacífica. As tensões na Europa já estavam presentes, tanto que, em 1914, tem início a Primeira Guerra Mundial e, alguns anos depois, a Segunda Guerra Mundial. A chamada educação para a paz teve em Bovet um dos mais importantes representantes. Já Claparède foi um psicólogo cujo ativismo extrapolou o campo da psicologia. Ele se envolveu em múltiplas atividades científicas, sociais e políticas. Claparède teve um papel fundamental na formação de Antipoff, o que pode ser comprovado com a leitura da correspondência trocada pelos dois (Ruchat, 2010). O instituto foi criado para se tornar um templo dedicado à infância e formar professores dentro do espírito científico da época. 
Além de se consolidar como o mais importante centro de formação de professores da Europa, o IJJR trabalhou em prol da proteção à infância. Desde fins do século XIX, a proteção à infância é uma preocupação crescente, sendo que essa política foi constituída, de um lado, pelas leis de escolarização obrigatória e, de outro, por leis que fixavam limites ao trabalho infantil (Hofstetter, Ratcliff, Schneuwly, 2012).

O IJJR constituiu-se como uma instituição comprometida com a infância, mais especificamente com a chamada infância anormal. O programa seguido por Antipoff, como aluna no IJJR, constava de 16 páginas, dividido em três partes: a criança, a educação e o ensino. A psicologia da criança, a educação dos anormais, a educação infantil, a educação moral, a organização escolar, a história da pedagogia e a sociologia da educação eram as matérias previstas. O médico François Naville e Alice Descoeudres se alternavam nas quintas-feiras como professores de cursos sobre crianças "anormais". As conferências de Descoeudres resultaram no livro A educação das crianças retardadas, publicado no Brasil pela Sociedade Pestalozzi de Minas Gerais em 1936. O curso de Descouedres era intitulado "Psicologia e pedagogia", e o de Naville, "Patologia e clínica das crianças anormais". A primeira turma, da qual Helena Antipoff era uma das alunas, teve 20 inscritos. Eram pessoas vindas de várias partes do mundo, interessadas em estudar em um centro de excelência sobre a infância (Borges, 2015).

Todo o contexto de formação de Antipoff contribuiu para que ela se dedicasse à causa das crianças "anormais" no Brasil. Ela havia optado por fazer uma formação humanista, em uma instituição comprometida com os ideais de justiça e de respeito pelo próximo.

Outra influência importante na formação de Antipoff foi o tempo em que viveu na Rússia. Em 1916, Antipoff retornou à sua terra natal. No período de seis anos em que ali permaneceu, trabalhou diretamente com os órfãos da guerra. Nessa época, centenas de abrigos foram criados, o que não evitava a intensa mobilidade de grupos de crianças abandonadas, de uma cidade para outra. O governo criou estações médico-pedagógicas, em especial ao longo das estações de trem, daí o nome. Nesses locais, Antipoff realizava a triagem das crianças, separando as "normais" das "anormais". Para cada perfil de criança havia uma instituição diferente: asilos para os chamados pela nosologia psiquiátrica da época de imbecis e idiotas, clínicas para os nervosos e delinquentes, escolas para os "normais" (Antipoff, 1924).

Tanto a formação no IJJR quanto a experiência na Rússia contribuíram para que a escolarização das crianças "anormais" se tornasse um de seus principais interesses. No Brasil havia uma carência de pessoas especializadas, de profissionais capacitados que pudessem trabalhar com essa população. Chegando ao país, Antipoff estabeleceu um trabalho expressivo, aliando a filantropia à ciência, tendo, como pano de fundo, os "anormais". Interessava-lhe acolher as crianças, mas também aprender sobre elas. Apesar de filantrópico, contando sempre com doações, o trabalho dos profissionais envolvidos com a SPMG deveria ter uma base científica, sendo organizado por meio dos métodos adequados e tendo os resultados analisados:

Mas não se iludem aqueles que pensam acabar com o mal com simples filantropia, com colônias de trabalho, com medidas empíricas e métodos diletantes. A assistência aos menores, como a luta contra epidemias endêmicas, possuem suas próprias técnicas. 
Estes métodos não se improvisam de um dia para outro, mas obedecem a um plano prévio e racionalmente organizado: matrícula, inquérito social, diagnóstico, seleção, regime médico-educativo diferenciado, educação individualizada, aprendizagem técnica, orientação e amparo do menor nos seus inícios profissionais, preparo do pessoal docente e subalterno - estas são as etapas definidas do programa de assistência (Antipoff, 1937, p.21).

\section{Sociedade Pestalozzi de Minas Gerais}

Helena Antipoff chegou ao Brasil em 1929. Assumiu funções como professora na Escola de Aperfeiçoamento de Professores de Belo Horizonte e a direção do Laboratório de Psicologia da mesma instituição. Conduziu todo o processo de homogeneização das classes escolares mineiras, estabelecendo as classes especiais, que já estavam previstas no Regulamento do Ensino Primário de 1927.

A proximidade com as crianças marginalizadas fez com que Antipoff decidisse reunir pessoas influentes da sociedade mineira e propor a criação de uma sociedade de assistência: “Art. $1^{\circ}$ - Fica instituída, nesta Capital, sob a denominação de 'Sociedade Pestalozzi', uma associação civil, destinada a proteger a infância anormal e preservar a sociedade e a raça das influências nocivas da anormalidade mental" (SPMG, 1933, p.11). "Anormal" seria toda criança que por condição hereditária, por acidentes mórbidos na infância, por falta de inteligência ou distúrbios de caráter não conseguisse se adaptar à vida social. A proteção previa ainda auxílio às classes especiais, organização de cursos, instalação de centros de consultas médico-pedagógicas, estabelecimento de centro de informações e estatísticas para coleta de dados, pesquisas sobre as crianças "anormais", criação de institutos, internatos e semi-internatos e publicação de obras a respeito de assuntos relacionados às crianças "anormais".

A sociedade seria formada por sócios que contribuiriam com uma cota mensal ou que pagariam uma cota única. Além desses, haveria sócios beneméritos, aqueles que prestassem serviços relevantes à instituição. O patrimônio seria constituído pela contribuição de sócios, subvenções, donativos e por bens que a sociedade adquirisse. Representantes da elite mineira da época se juntaram a Antipoff na empreitada.

Apesar de já existir no sul do país um Instituto Pestalozzi, a Sociedade Mineira também levou o nome do pedagogo suíço. A marca do nome Pestalozzi ${ }^{3}$ imprimiu à sociedade o espírito filantrópico. O grande diferencial da proposta educativa realizada por Pestalozzi na Suíça foi, sem dúvida, o acolhimento das diferenças individuais. Crianças de diferentes nacionalidades, religiões e camadas sociais encontravam espaço em sua escola.

O nome escolhido para a sociedade estava carregado dessa simbologia. Pestalozzi era admirado por Antipoff exatamente pelo fato de ter dedicado sua vida aos outros, havia vivido uma vida de doação e de humildade. Desde o início, a vocação da SPMG foi oferecer apoio à população constituída pelas crianças "anormais" por meio de seu caráter assistencialista e filantrópico.

A primeira iniciativa da SPMG foi o apoio às classes especiais, a partir da promoção de visitas de alunas da Escola de Aperfeiçoamento de Professores de Belo Horizonte a essas 
classes. As professoras que frequentavam a Escola de Aperfeiçoamento eram normalistas selecionadas entre as melhores de suas cidades para realizar na capital do estado uma formação muito consistente, que incluía conhecimentos em educação especial. Nas visitas, as professoras das classes especiais recebiam orientação sobre as atividades indicadas para os alunos, bem como ajuda financeira para compra de materiais diversificados que as pudessem auxiliar no ensino. Outros materiais eram adquiridos pela SPMG e disponibilizados para as professoras.

Em 1933, tiveram início as atividades do Consultório Médico-Pedagógico, que foi idealizado a partir da experiência de Antipoff no IJJR. Os médicos, a princípio, atendiam em seus próprios consultórios, de forma voluntária, abrindo espaço em suas agendas para atender as crianças "anormais". Posteriormente, com a criação do Instituto Pestalozzi, o consultório foi estabelecido na instituição. Essa iniciativa foi pioneira no estado de Minas Gerais, pois as crianças passavam também por uma consulta psicológica e por uma avaliação pedagógica. Depois os profissionais se reuniam e deliberavam sobre o caso.

Em 1934, foi inaugurado um pavilhão para abrigar a Associação de Assistência ao Pequeno Jornaleiro, que recebeu crianças que viviam nas ruas da capital mineira. As crianças que habitavam as ruas de Belo Horizonte, muitas delas vendedoras de jornais, dormiam debaixo das marquises dos prédios. O governo de Minas doou um terreno pertencente ao estado, e a SPMG fez uma intensa campanha para que fosse construído um imóvel que essas crianças pudessem habitar, conseguindo recursos para a construção de um enorme prédio, onde as crianças recebiam alimentação e alojamento. Para frequentar a associação, os meninos deveriam estar matriculados em escolas. Como o trabalho de maiores de 12 anos era permitido na época, as crianças poderiam vender jornais ou executar outras funções, desde que estudassem.

A população constituída por meninos que estavam abaixo da linha da pobreza, ou seja, miseráveis, também era considerada "anormal". Uma das mais importantes realizações da SPMG foi a proposta desse serviço pioneiro no Brasil. ${ }^{4}$ Embora essa iniciativa não constasse de forma explícita nos estatutos da SPMG, um dos objetivos da sociedade seria amparar as crianças abandonadas ou desviadas dos caminhos próprios da infância. Para lançar a campanha de criação do serviço, Helena Antipoff ministrou uma palestra para os membros da Sociedade Pestalozzi, durante a qual citou a Declaração de Genebra, promulgada em 1923 pela União Internacional de Socorro às Crianças. Na declaração, ficava reconhecida a condição especial de ser criança. Ela deve ser a primeira a receber socorro; ser educada de maneira a poder ganhar a vida e ser protegida da exploração; ser educada com a ideia de que suas melhores qualidades devem estar a serviço de seus irmãos. A declaração afirmava ainda que crianças órfãs e abandonadas deveriam ser recolhidas e socorridas. Essa referência que Antipoff faz à Declaração de Genebra tinha a intenção de sensibilizar a audiência acerca das crianças trabalhadoras e do dever da sociedade de proteger essa população (Antipoff, 1934).

Em 1935, foi inaugurado o Instituto Pestalozzi. Uma escola especial, que funcionava como internato, onde as crianças estudavam e aprendiam pequenos ofícios. Desde o início, o instituto já estava atrelado ao governo estadual, embora o projeto fosse da SPMG. A Sociedade Pestalozzi ganhou um terreno como doação, e o governo de Minas 
Gerais construiu o prédio do instituto. No terreno já havia sido instalado um barracão para sediar o Consultório Médico-Pedagógico, com recursos próprios da SPMG. Mas o prédio maior, chamado de Pavilhão, foi obra do governo do estado de Minas Gerais. O corpo docente e administrativo também foi cedido pelo governo mineiro. O Consultório Médico-Pedagógico, que já funcionava desde a criação da SPMG, passou a fazer parte do instituto, mantendo a gratuidade para as crianças que não pudessem pagar e cobrando das que tivessem condições.

Por fim, em 1940, é criada a Fazenda do Rosário. Em 1939, com a formação da primeira turma do Instituto Pestalozzi no curso primário, surge a necessidade de uma nova instituição que pudesse receber essas crianças:

Sob a pressão da necessidade de assistir esses menores, que não se achavam em condições de continuar os estudos em outros estabelecimentos nem de se empregar em ocupações profissionais, resolveu a Sociedade Pestalozzi adquirir uma propriedade rural e nela instalar uma Escola-Granja para menores desajustados e crianças excepcionais (Fazenda do Rosário, 1952, p.1).

O documento consultado afirma que a Fazenda do Rosário, em seus primeiros anos de funcionamento, foi um órgão vital da Sociedade Pestalozzi de Minas Gerais. Embora a iniciativa de sua criação tenha sido da SPMG, com sua vertente filantrópica, o fortalecimento do complexo educacional foi consolidado a partir da parceria com o poder público.

A intensa e estreita relação entre público e privado, entre filantropia e Estado, pode ser atestada tanto na publicação Infância Excepcional: Estudo, Educação e Assistência ao Excepcional, da SPMG (1968), quanto na correspondência pessoal de Antipoff.

\section{A filantropia da SPMG na revista Infância Excepcional e outros documentos}

A revista Infância Excepcional: Estudo, Educação e Assistência ao Excepcional foi uma importante fonte de divulgação das ações da Sociedade Pestalozzi entre 1933 e 1979. Apesar de publicado de forma irregular, o periódico constituiu-se como fonte de informação sobre a SPMG. Sua organização em termos de numeração e de ano é a seguinte:

Os números 1, 2 e 3 correspondem aos números 12, 16 e 20 das Publicações da Secretaria da Educação e Saúde Pública de Minas Gerais, com o título 'Infância Excepcional', nos anos de 1933, 1934 e 1937. Os números 4, 5 e 6 publicados sob o título 'Assistência ao Excepcional' como Suplementos do 'Mensageiro Rural', órgão do Instituto Superior de Educação Rural (ISER) da Fazenda do Rosário, nos anos de 1962 a 1965. O No 7, publicado com o título 'Boletim Pestalozzi' - Suplemento $n^{\circ} 7$ do 'Mensageiro Rural', $2^{\circ}$ semestre de 1965 (SPMG, 1966, contracapa).

Existem ainda dois boletins denominados Infância Excepcional, um de 1963, outro de 1965. Não fazem parte da coleção mencionada, mas também são fontes importantes de investigação e constituíram o escopo de análise desta pesquisa.

Sem ter uma fonte de renda fixa e doações garantidas, a Sociedade Pestalozzi iniciou, desde sua fundação até a década de 1960, a tarefa constante de buscar donativos para manutenção de seus trabalhos. Os pedidos poderiam ser explícitos ou estar nas entrelinhas 
de suas publicações e nas sutilezas dos discursos de seus membros. O objetivo central desses textos era pedir doações por meio da sensibilização do leitor. Outra forma de estimular as contribuições era apresentar ao leitor os trabalhos realizados pela SPMG e sua importância para a sociedade. Em seguida, os autores apresentavam os gastos para manutenção dos trabalhos e a informação de que as finanças não andavam bem, deixando subentendido no texto a necessidade de recebimento de apoio.

No prefácio da primeira edição, o vice-presidente da Sociedade Pestalozzi de Minas Gerais anuncia que o motivo da publicação seria uma apresentação dos trabalhos realizados e, ao mesmo tempo, "um apelo à inteligência, ao coração e à generosidade do nosso povo em prol do melhoramento mental e moral das crianças retardadas" (Negromonte, 1933, p.7). Assim, a publicação da revista era ao mesmo tempo um meio de divulgação dos trabalhos e um instrumento de arrecadação de fundos para manutenção da instituição.

Em 1933 e 1934 é divulgado, entre outras ações realizadas pela instituição, o auxílio financeiro que a SPMG prestava às classes especiais dos grupos escolares mineiros. No balancete financeiro publicado é possível verificar que sua receita se constituía basicamente de doações e mensalidades dos sócios da instituição, enquanto as despesas foram essencialmente com materiais de uso pedagógico. Em um dos artigos da publicação de 1934, o secretário geral da SPMG destaca que:

É confortador também assinalar que, na consecução dos nossos objetivos, não nos faltaram a simpatia, o interesse e o amparo da Sociedade, da Igreja, da Imprensa e do Governo, na elevada compreensão de suas finalidades. Associação particular, teve suas rendas mantidas exclusivamente pela modesta contribuição popular ... do Governo, na pessoa ilustre de Noraldino Lima, perfeitamente integrado no magno problema da infância excepcional, todas as facilidades, incentivo e apoio material temos amplamente recebido (Gomes, 1934, p.28).

Gomes se refere aqui a Noraldino Lima, secretário de Educação e Saúde Pública de Minas Gerais. A parceria estabelecida desde o início com representantes do estado de Minas Gerais e, depois, do Brasil, foi muito importante para que a SPMG conseguisse realizar tantas ações.

Na Assembleia Geral anual da Sociedade Pestalozzi de Minas Gerais de 1936 foi apresentado o relatório de 1935. Nele foram expostas algumas dificuldades financeiras vivenciadas pela instituição. Entre os gastos previstos estavam a necessidade de realização de algumas expansões no Instituto Pestalozzi e a melhoria da alimentação fornecida aos estudantes. No Instituto Pestalozzi, muitas vezes o público e o privado se misturavam, o que dificultava a distinção entre o que era realização do governo de Minas Gerais e o que era promovido pela iniciativa privada.

Algumas subvenções do governo também foram concedidas à Sociedade Pestalozzi. Em 1936, a obra A educação das crianças retardadas, de Alice Descouedres, foi editada pela Secretaria de Educação e metade de seus exemplares foi doada para a Sociedade Pestalozzi, para que o dinheiro de sua venda fosse revertido para a instituição. Em setembro de 1936, a Secretaria do Interior e a Secretaria da Agricultura prestaram auxílio financeiro para a organização de uma exposição na Feira de Trabalho de Menores. E, em outubro do mesmo ano, o Ministério da Educação concedeu uma verba para apoiar as pesquisas da Sociedade Pestalozzi na área de endocrinologia. 
Na década de 1940, as ações da SPMG foram concentradas na Fazenda do Rosário, e as parcerias com o poder público continuaram. A começar pelo próprio estabelecimento do Complexo do Rosário. O terreno foi adquirido com dinheiro de doações, arrecadado por meio da campanha dos Diários Associados, sob direção de Assis Chateaubriand.

Associação beneficente, sem recursos financeiros, conseguiu levantar em poucos meses um modesto capital, com donativos e subscrições entre amigos e com a participação principal dos 'Diários Associados', cujo diretor, Dr. Assis Chateaubriand remeteu 86 contos de réis, resultado de uma intensa 'campanha' em benefício da Sociedade Pestalozzi pelos jornais do Rio, de Minas e outros Estados. De posse de 120 contos de réis, quantia então de bastante importância, foi possível, após intensas procuras e viagens, comprar um sítio de quarenta alqueires, nas imediações (Fazenda do Rosário, 1952, p.2; destaques no original).

O prédio para a escola primária foi construído com verba do Instituto Nacional de Estudos Pedagógicos (Inep), e a residência dos alunos internos com verba da Campanha Nacional da Criança do Ministério da Educação e Cultura (MEC) (Antipoff, 1963). Outras conquistas relacionadas à expansão, à melhoria e à manutenção da Fazenda do Rosário também contaram com o auxílio do Estado. Da disponibilização de funcionários à construção de prédios, a Sociedade Pestalozzi se beneficiou das parcerias realizadas com o poder público. Ao mesmo tempo, a educação pública obteve serviços prestados pela iniciativa privada e conquistou melhorias que, a princípio, foram realizadas pela Sociedade Pestalozzi e, posteriormente, assumidas pelo governo mineiro.

A Fazenda do Rosário iniciou suas atividades como um internato rural para crianças com deficiência. Mas outras instituições educativas foram sendo criadas, como: Escolas Reunidas Dom Silvério, para o ensino primário; o Ginásio Normal Oficial Rural Caio Martins, um internato para rapazes; o Ginásio Normal Oficial Rural Sandoval Azevedo, para moças; o Clube Agrícola João Pinheiro, para o ensino de técnicas agrícolas (Campos, 2010). Destacase, ainda, a criação do Instituto Superior de Educação Rural (Iser), criado oficialmente pelo decreto n.4.830 de 12 de dezembro de 1955 (Minas Gerais, 12 dez. 1955). O governo do estado de Minas Gerais estabeleceu novamente uma parceria com a SPMG para regularizar o funcionamento de um órgão de ensino de nível superior destinado à educação rural. No Iser, ocorriam os cursos de educação emendativa, que tiveram início em 1951, subsidiados por governos estaduais ou pelo governo federal. A expressão educação emendativa constava na legislação estadual e federal sobre a educação especial e foi utilizada algumas vezes como sinônimo de educação especial. Trata-se do ensino ofertado para as crianças consideradas excepcionais. O último registro encontrado desses cursos é de 1971, o quarto Curso de Especialização em Educação de Excepcionais (Casemiro, 2018).

É possível afirmar que a Sociedade Pestalozzi de Minas Gerais recebeu auxílio do poder público ao mesmo tempo que prestava serviços relevantes para a Secretaria de Educação. Tratava-se de uma parceria, uma troca.

A partir da década de 1960, é possível verificar uma mudança nas edições da revista Infância Excepcional: Estudo, Educação e Assistência ao Excepcional. Essa mudança reflete principalmente uma alteração que já estava em curso: se, nos anos iniciais, a SPMG dependia muito de doações, e o poder público era o coadjuvante, contribuindo com o 
necessário, a partir de meados da década de 1950 a SPMG passa a depender cada vez mais da ajuda estatal. Se antes a parceria entre a SPMG e o estado de Minas se dava de maneira quase informal, a partir da década de 1950 a implementação de políticas públicas para a educação especial provoca a necessidade de que haja uma formalização das parcerias. A apresentação de uma enumeração de doações ou de subvenções do poder público e os pedidos constantes de doações cederam lugar à difusão das políticas públicas destinadas à educação especial e à divulgação de atividades financiadas por verba pública concedida por meio de políticas específicas.

Em 1960, o Ministério da Educação e Cultura publicou o decreto n.48.961, instituindo a Campanha Nacional de Educação e Reabilitação de Deficientes Mentais (Cademe). Em seu artigo terceiro determinava-se que a Cademe tinha "por finalidade promover em todo o território nacional a educação, treinamento, reabilitação e assistência educacional das crianças retardadas e outros deficientes mentais de qualquer idade ou sexo" (Brasil, 22 set. 1960), cooperando, estimulando, incentivando e mantendo parcerias com instituições públicas e privadas que se ocupavam das crianças com deficiência mental. Assim, a Cademe, sem participar diretamente dos trabalhos, fomentaria as ações promovidas pelas instituições públicas e privadas.

Em 1961, é publicada a Lei de Diretrizes e Bases da Educação Nacional (LDB), e pela primeira vez a educação dos excepcionais recebeu um capítulo à parte, além de dois artigos específicos para essa área. O artigo 88, informando que "a educação de excepcionais, deve, no que for possível, enquadrar-se no sistema geral de educação, a fim de integrá-los na comunidade" (Brasil, 20 dez. 1961). E o artigo 89, prevendo que "toda iniciativa privada considerada eficiente pelos conselhos estaduais de educação, e relativa à educação de excepcionais, receberá dos poderes públicos tratamento especial mediante bolsas de estudo, empréstimos e subvenções" (Brasil, 20 dez. 1961).

Tanto o decreto da Cademe quanto a LDB/1961 passaram a garantir às instituições privadas a possibilidade de financiamento e benefícios para manutenção de suas atividades. Segundo a Sociedade Pestalozzi, "do âmbito da iniciativa privada, a educação do excepcional passou a encontrar apoio e colaborações oficiais" (SPMG, ago. 1962, p.1). Essa nova fase se refletiu nos números da revista Infância Excepcional: Estudo, Educação e Assistência ao Excepcional.

Os pedidos de doações e os agradecimentos pelo que foi recebido não desapareceram das edições, como é possível notar em alguns artigos publicados na década de 1960, intitulados "Um apelo" (1963), "Ajude a Sociedade Pestalozzi de Minas Gerais" (1964), e "Um apelo ao coração" (1965). Mas o financiamento das atividades da Sociedade Pestalozzi deixou de ser um tema recorrente. As entrelinhas dos textos não traziam mais com frequência pedidos de doação. Não havia mais tentativas de sensibilização da sociedade ou de órgãos públicos, como anteriormente. A partir da década de 1960, a revista traz artigos que apresentam os benefícios garantidos pela legislação vigente, as formas de conseguir este auxílio e, por vezes, a dotação orçamentária disponível.

Em 1968, foi publicado o Relatório do Grupo de Trabalho constituído pelo secretário de Estado de Educação de Minas Gerais, por meio de solicitação da Cademe. Helena Antipoff presidiu esse grupo e elaborou um estudo que respondia algumas questões relacionadas à 
educação do excepcional. Como conclusão da pesquisa, o grupo fez algumas sugestões para melhorar o atendimento educacional a esse público. Entre elas, quanto ao financiamento das ações, encontram-se: estabelecimento de porcentagem fixa destinada à educação especial em todos os planos de financiamento da educação, especialmente quando se tratar da LDB/61 art. 88 e 89; financiamento mediante bolsas de estudos para o deficiente mental e inadaptado nas instituições particulares; inclusão da assistência a instituições de deficientes e inadaptados no plano de isenção do imposto de renda; provisão de créditos para ajudar os pais que precisarem de apoio para despesas de pensão e transporte das crianças em regime de internato; solicitação de apoio da Organização das Nações Unidas para a Educação, a Ciência e a Cultura (Unesco) para estabelecimento de medidas que auxiliem na arrecadação de mais verba e apoio técnico às ações relacionadas à educação especial; criação de um selo pró-deficientes mentais e inadaptados, cuja renda seria destinada à construção de prédios para instituições de atendimento a esse público (SPMG, 1968).

Antipoff ainda participou da criação das Associações de Pais e Amigos dos Excepcionais, esteve à frente do Departamento Nacional da Criança (1946-1956), fundou a Sociedade Pestalozzi do Brasil, com sede no Rio de Janeiro e atuou na Cademe (Campanha Nacional de Educação e Reabilitação de Deficientes Mentais) e no Cenesp (Centro Nacional de Educação Especial). Os professores e pesquisadores que ela formou assumiram lugares estratégicos na constituição das políticas públicas voltadas às pessoas com deficiência (Borges, Campos, 2016).

As boas relações políticas de Helena Antipoff com o governo de Minas Gerais se repetiram em relação ao governo federal. Sua formação na Europa, extremamente qualificada, lhe conferia um lugar privilegiado. Os políticos confiavam nela, como pode ser constatado no trecho da carta abaixo:

Às pressas transmito-lhe a boa notícia dada ontem pelo Sr. Alcimar, chefe da contabilidade do Inep - da remessa dos CR \$ 875.078,00 - OT 1047 - 5.12.957 do Banco do Brasil. A ordem foi em nome do Iser aos cuidados de Helena Antipoff. A quantia a receber seria 876.004,00, parte do saldo do acordo de 19.1.1956, concedendo auxílio para complementação das obras, sendo que 926,00 corresponde à despesa bancária. Mais uma vez, Dr. Anísio revelou ser seu amigo, atendendo tão prontamente seu pedido. Não há nada como suas entrevistas pessoais! (Carneiro, 8 dez. 1957).

A correspondência estabelecida entre Helena Dias Carneiro ${ }^{5}$ e Helena Antipoff é profícua em citações sobre Anísio Teixeira, figura pública influente no campo da educação. As questões financeiras também são assunto recorrente. Helena Dias Carneiro, moradora do Rio de Janeiro, então capital federativa do Brasil, fazia o elo entre Antipoff e os políticos influentes no campo da educação.

A partir do estabelecimento da Fazenda do Rosário, além da assistência aos excepcionais que continuou ocorrendo, a formação de professores e de pessoal especializado no campo da educação especial que pudesse continuar sua obra constituiu-se em um objetivo. A parceria com o poder público se manteve, e, como já dito, se no início a SPMG dependia de maneira mais direta da filantropia, apesar do auxílio prestado pelo Estado, em fins da década de 1950 e início da década de 1960 a SPMG passa a contar com novas formas de parceria com o poder público. 
Acabo de conversar com o Dr. Gustavo Lessa sobre o que a senhora deverá acertar com o Ministro sobre a verba para a manutenção do Iser e dos cursos da Campanha. Nosso amigo aconselha que a senhora faça um ORÇAMENTO de todas as despesas necessárias para o ano de 1958 e apresente ao Ministro quando de sua visita ao Rosário - sendo feito este apelo aí, será mais interessante do que no Ministério (Carneiro, 8 dez. 1957; destaque no original).

Gustavo Lessa assumiu diversos cargos importantes na área educacional ao lado de Anísio Teixeira. A importância do nome de Helena Antipoff pode ser atestada em outra carta:

Concordou, então, Dr. Anísio, que a senhora em vez de partir no dia 21 deste, transfira a viagem para o dia $1^{\circ}$ de maio. Até o dia $1^{\circ}$, o estudo será sobre o ensino primário, depois é que abordarão a formação de professores. Foi bastante categórico afirmando que a senhora não indo, não será designado outro representante para Minas, pois D. Benedita Melo jamais poderá substituir a senhora, ela só poderia ir como assistente, mas no momento todas as despesas vão correr pelo Ministério da Educação, pois não contam mais com auxílio do Itamarati, ele pede que a senhora desista de sua assistente (Carneiro, 9 abr. 1956).

Figura respeitada no cenário nacional, Helena Antipoff iniciou uma obra filantrópica em que o estado teve papel fundamental. Criando a demanda, Helena Antipoff estabeleceu a necessidade dos serviços. O Consultório Médico-Pedagógico, por exemplo, não existia. Mas ao iniciar os atendimentos, uma demanda foi criada e sua necessidade passou a ser crescente. Repetidamente, nas instituições propostas por Antipoff, os serviços depois de criados passaram a ser essenciais. Ao se tornarem essenciais, cabia ao poder público assumir sua gestão. Antipoff se antecipava ao governo, percebendo as necessidades ainda implícitas de serviços. Iniciava a obra e depois convocava o governo a assumir a responsabilidade por sua manutenção. Dessa forma, pressionava o poder público a assumir a responsabilidade pela educação das crianças consideradas "anormais" na época, além de outras iniciativas.

\section{Considerações finais}

O entrelaçamento entre poder público e iniciativa privada fica evidenciado no caso da Sociedade Pestalozzi de Minas Gerais. O estudo de fontes primárias permitiu afirmar que Helena Antipoff exerceu um papel fundamental na constituição do campo da educação especial no Brasil. A partir da filantropia, iniciada com a criação da SPMG em 1932, Antipoff construiu instituições que atravessaram o tempo e permanecem em atividade até hoje, além de costurar alianças com diferentes governos e agentes públicos. Sua influência se deve à sólida formação realizada na Europa no Instituto Rousseau e ao trabalho realizado com as crianças abandonadas na Rússia soviética.

Além de criar as instituições que acolheram tantas crianças ao longo dos anos, Antipoff se dedicou à formação de professores e de pessoal especializado no campo da educação especial. Os cursos ofertados na Fazenda do Rosário eram frequentados por pessoas de todo o país. Politicamente, ela participou de grupos de trabalho que elaboraram diversas leis sobre a educação especial. Era consultada sempre que o assunto dizia respeito às crianças "anormais". Estabeleceu parcerias bem-sucedidas entre a sociedade civil e o poder público. 
A educação especial no Brasil como campo expandiu-se e teve reconhecimento a partir de iniciativas que foram adaptadas ao contexto local por Antipoff a partir de sua formação no IJJR.

\section{AGRADECIMENTOS}

Ministério da Ciência, Tecnologia e Inovação. Conselho Nacional de Desenvolvimento Científico e Tecnológico. Fundação de Amparo à Pesquisa do Estado de Minas Gerais.

\section{NOTAS}

${ }^{1}$ Antipoff manteve-se como presidente da sociedade de 1932 até 1945.

2 Para mais informações sobre o protagonismo de Genebra na questão dos Direitos Humanos, ver Traz (1929), em que o autor constrói a narrativa sobre o "espírito de Genebra" a partir da fundação da Sociedade das Nações e dos grandes nomes do humanismo mundial, como Calvino e Rousseau.

${ }^{3}$ Johann Heinrich Pestalozzi (1746-1827), natural de Zurique, Suíça. Educador.

${ }^{4}$ Posteriormente, em 1940, foi criada uma Casa do Pequeno Jornaleiro no Rio de Janeiro, por Darcy Vargas, esposa do presidente Getúlio Vargas.

${ }^{5}$ Helena Dias Carneiro, fiel colaboradora de Helena Antipoff, desenvolveu e dinamizou atividades vitais para a Federação das Sociedades Pestalozzi. Foi ela quem apresentou, em 1979, o projeto de criação do Centro de Documentação e Pesquisa Helena Antipoff (CDPHA).

\section{REFERÊNCIAS}

ANTIPOFF, Helena.

Sociedade Pestalozzi de Minas Gerais: 1932-1962 - Notas por Helena Antipoff. Infância Excepcional, ano 1, n.1, p.10-27. 1963.

ANTIPOFF, Helena.

Assembleia Geral de 1936. Infância Excepcional, n.20, p.7-21 (Boletim da Secretaria da Educação e Saúde Pública de Minas Gerais). 1937.

ANTIPOFF, Helena.

Assistência aos menores desamparados, trabalhadores de rua. Infância Excepcional, n.16, p.101-111 (Boletim da Secretaria da Educação e Saúde Pública de Minas Gerais). 1934.

ANTIPOFF, Helena.

L'expérience russel: l'éducation sociale des enfants. Semaine Littéraire, v.32, n.1615, p.592594. 1924.

BORGES, Adriana Araújo Pereira.

De anormais a excepcionais: história de um conceito e de práticas inovadoras em educação especial. Curitiba: CRV. 2015.

BORGES, Adriana Araújo Pereira; CAMPOS, Regina Helena de Freitas.

A influência de Helena Antipoff na educação especial brasileira: entre a militância e a ciência. In: Congresso Brasileiro de Educação Especial, 7., 2016, São Carlos. Anais... São Paulo: Galoá. 2016.
BRASIL.

Lei n.4.024, de 20 de dezembro de 1961. Fixa as Diretrizes e Bases da Educação Nacional. Disponível em: <http://www.planalto.gov.br/ CCIVil_03/leis/L4024.htm>. Acesso em: jul. 2018. 20 dez. 1961.

\section{BRASIL.}

Decreto n.48.961, de 22 de setembro de 1960. Institui a Campanha Nacional de Educação e Reabilitação de Deficientes Mentais. Disponível em: <http://www2.camara.leg.br/legin/fed/ decret/1960-1969/decreto-48961-22-setembro1960-388634-publicacaooriginal-1-pe.html>. Acesso em: jun. 2018. 22 set. 1960.

CAMPOS, Regina Helena Freitas.

Helena Antipoff. Recife: Editora Massangana. (Coleção Educadores MEC). 2010.

CAMPOS, Regina Helena de Freitas; LOURENÇO, Érika; ANTONINI, Iabel Gontijo. Introdução: Helena Antipoff e a psicologia no Brasil. In: Campos, Regina Helena Freitas (Org.). Helena Antipoff: textos escolhidos. São Paulo: Casa do Psicólogo; Brasília: Conselho Federal de Psicologia. 2002.

CARNEIRO, Helena Dias.

Carta a Helena Antipoff. Arquivo da Sala Helena Antipoff. Correspondências (Centro de Documentação e Pesquisa Helena Antipoff, Belo Horizonte). 8 dez. 1957. 
CARNEIRO, Helena Dias.

Carta a Helena Antipoff. Arquivo da Sala Helena Antipoff. Correspondências (Centro de Documentação e Pesquisa Helena Antipoff, Belo Horizonte). 9 abr. 1956.

CASEMIRO, Maria de Fátima Pio.

Formação de professores para a educação especial: a experiência de Helena Antipoff e seus colaboradores na Fazenda do Rosário na década de 1960. Tese (Doutorado em Psicologia, Psicanálise e Educação) - Universidade Federal de Minas Gerais, Belo Horizonte. 2018.

FAZENDA DO ROSÁRIO.

História da Fazenda do Rosário. Arquivo do Memorial Helena Antipoff. Pasta Fazenda do Rosário (Centro de Documentação e Pesquisa Helena Antipoff, Ibirité). 1952.

GOMES, Fernando de Magalhães. Uma exposição do dr. Fernando de Magalhães Gomes. Infância Excepcional, n.16, p.27-30. (Boletim da Secretaria da Educação e Saúde Pública de Minas Gerais). 1934.

HOFSTETTER, Rita; RATCLIFF, Marc; SCHNEUWLY, Bernard.

Cent ans de vie: la faculté de psychologie et des sciences de l'education, héritière de l'Institut Rousseau et de l'ère piagetienne, 1912-2012. Genève: Georg. 2012.

MINAS GERAIS.

Decreto n.4.830 de 12 de dezembro de 1955. Cria o Instituto Superior de Educação Rural. Arquivo do Memorial Helena Antipoff. Pasta Fazenda do Rosário (Centro de Documentação e Pesquisa Helena Antipoff, Ibirité). 12 dez. 1955.

NEGROMONTE, Álvaro.

Prefácio. Infância Excepcional, n.12, p.7. (Boletim da Secretaria da Educação e Saúde Pública de Minas Gerais). 1933.
RATCLIFF, Marc J.

Atalho analógico e reconstrução microhistórica: as origens do laboratório de psicologia experimental de Genebra em 1892. Mnemosine, v.14, n.1, p.246-273. 2018.

RIZZINI, Irene; PILOTTI, Francisco.

$A$ arte de governar crianças: a história das políticas sociais, da legislação e da assistência à infância no Brasil. São Paulo: Cortez. 2009.

RUCHAT, Martine (Ed.).

Édouard Claparède-Hélène Antipoff:

correspondance (1914-1940). Firenze: Leo

Olschki. 2010.

SPMG.

Sociedade Pestalozzi de Minas Gerais. Relatório de Grupo de Trabalho pró-Deficiente Mental. Infância Excepcional, n.11, p.71-141. 1968.

SPMG.

Sociedade Pestalozzi de Minas Gerais. Razão do n.8. Infância Excepcional, n.8. 1966.

SPMG.

Sociedade Pestalozzi de Minas Gerais. Lei de Diretrizes e Bases. Mensageiro Rural. Assistência ao excepcional (suplemento). p.1. ago. 1962.

SPMG.

Sociedade Pestalozzi de Minas Gerais. Infância Excepcional, n.12, p.11-15. (Boletim da Secretaria da Educação e Saúde Pública de Minas Gerais). 1933.

TRAZ, Robert de.

L'Esprit de Genève. Genève: Grasset. 1929.

WERNER, Michael; ZIMMERMANN, Bénédicte. Penser l'histoire croisée: entre empirie et réflexivité. Paris: Seuil. p.15-49. 2004. 